\title{
La cooperación internacional \\ entre Perú y China (2011-2016)
}

\section{International Cooperation Between Peru and China (2011-2016)}

DOI: 10.32870/mycp.v9i26.616

Johana Lucar ${ }^{1}$

\section{Resumen}

El aumento de la interacción económica, política y cultural entre China y Perú ha sido documentado en numerosos escritos. Sin embargo, un tema que ha sido poco abordado es el de la cooperación internacional entre ambos países. Por ello, la presente investigación tiene por objetivo analizar la cooperación internacional entre Perú y China durante el periodo 2011-2016 mediante una metodología descriptiva, analítica e inductiva, y el uso de fuentes escritas primarias y secundarias. El principal resultado encontrado es que, para China, su cooperación internacional es un instrumento de política exterior que le ayuda a conseguir su objetivo económico en Perú: el mayor aprovechamiento de sus recursos minerales. Finalmente, los aportes de la presente investigación son brindar información detallada acerca de un tema poco estudiado de las Relaciones Internacionales y ser un punto de partida para posteriores documentos académicos.

Palabras clave: Cooperación Internacional, Perú, China, política exterior, Relaciones Internacionales.

\begin{abstract}
The increase in economic, political and cultural interaction between China and Peru has been documented in numerous papers. However, an issue that has been poorly addressed is international cooperation between the two countries. Therefore, this research aims to analyze international cooperation between Peru and China through a descriptive, analytical and inductive methodology, and the use of primary and secondary sources. The main result of this document is that China is using its international cooperation as a foreign policy instrument that helps it to achieve its economic objective in Peru: greater use of its mineral resources. Finally, the report of the present investigation is to provide more specific information on a topic that has been poorly studied in International Relations and to be a starting point for later academic documents.
\end{abstract}

Key Words: Foreign Aid, Peru, China, Foreign Policy, International Relations.

Articulo recibido el 08 de febrero de 2019 y dictaminado el 05 de septiembre de 2019.

1. Universidad de Piura. Calle José Olaya 131, Miraflores Lima, Perú. ORCID: https://orcid.org/00000001-5176-5204. Correo electrónico: lucarjohana@gmail.com 


\section{Introducción}

La historia de las relaciones de la República Popular de China (en adelante, China) con América Latina comenzó muchos siglos atrás. La influencia que este país tiene en la actualidad en dicha región se puede analizar teniendo en cuenta los vínculos comercial ${ }^{2}$ (exportaciones e importaciones de bienes y servicios; y negociaciones comerciales), diplomático ${ }^{3}$ (número de visitas diplomáticas al más alto nivel) y de cooperación.

Específicamente, la relación entre la República de Perú (en adelante, Perú) y China data del siglo XIX, y desde entonces los lazos entre ambos países se han ido estrechando en los ámbitos culturales, políticos y económicos. Existen numerosos estudios que han indagado acerca de dichas relaciones, pero uno de los temas que no ha sido investigado de manera exhaustiva ha sido la cooperación internacional entre ambos países.

La cooperación internacional es una de las herramientas de política exterior más utilizadas. Históricamente, los países desarrollados han empleado este instrumento para la obtención de determinados propósitos en el ámbito internacional, sin tener que recurrir a medios coercitivos que podrían tener consecuencias de diferente índole. En las últimas décadas, la cooperación internacional ha venido atravesando por un periodo de reorganización y cambios. Uno de ellos es el protagonismo de los países en desarrollo como ofertantes de cooperación internacional, conforme el esquema de la Cooperación Sur Sur.

2. En relación al vínculo comercial, en los últimos años se ha evidenciado un mayor acercamiento comercial entre China y América Latina, aunque todavía hoy está en niveles relativamente reducidos, tal como lo afirma la CEPAL: "En el periodo 2005 - 2011, las tasas de crecimiento de las exportaciones de China hacia América Latina y el Caribe y de sus importaciones desde la región excedieron significativamente a las de sus exportaciones e importaciones totales. Así, la participación de América Latina y el Caribe ha crecido hasta representar en el 2011 el 6\% de las exportaciones chinas y el $7 \%$ de sus importaciones". Es interesante anotar que, en las últimas décadas, China se ha convertido en uno de los principales importadores mundiales de productos primarios agrícolas, minerales y de combustibles. En este sentido, al ser América Latina y el Caribe fuente importante de producción de estos artículos, se puede inferir que el interés comercial de China hacia esta región seguirá aumentando en el futuro (Comisión Económica para América Latina y el Caribe [CEPAL], 2012).

3. Fuera del plano político y económico, las relaciones entre China y ALC que más han crecido han sido las referidas al intercambio académico. China no escatima esfuerzos en aumentar los intercambios que permitan un mayor conocimiento de China en ALC, para lo cual, en los últimos años, han proliferado numerosos Institutos Confucio en la región y China otorga anualmente miles de becas para viajar a allí. Tomado de la página web de la Oficina del Consejo Internacional del Idioma Chino, disponible en http://english.hanban.org/, consultado en marzo del 2018. 
Debe tenerse en cuenta que el concepto cooperación internacional tiene numerosas definiciones. De hecho, no sólo es usado en el campo de las Relaciones Internacionales, sino también en los de la Economía, el Derecho, la Sociología, etc., como un sinónimo de "ayuda externa", "ayuda humanitaria" o "ayuda internacional", cuando se quiere aludir a la solidaridad entre diferentes agentes. Para efectos del presente estudio se empleará el concepto cooperación internacional referido al de las Relaciones Internacionales: "Por cooperación internacional entendemos toda relación entre actores internacionales orientada a la mutua satisfacción de intereses o demandas, mediante la utilización complementaria de sus respectivos poderes en el desarrollo de actuaciones coordinadas y/o solidarias" (Calduch, 1995, p. 76).

De esta manera, mediante una metodología descriptiva, analítica e inductiva, y mediante el uso de fuentes escritas primarias y secundarias, este trabajo busca exponer información acerca de la cooperación internacional entre Perú y China, que en el pasado no ha sido investigada a conciencia. Consideramos que en este punto residen la importancia y la trascendencia del presente estudio.

El objetivo general de esta investigación es analizar la cooperación internacional entre Perú y China de 2011 a 2016. Los objetivos específicos son: indagar las características de la cooperación china y describir las características de la cooperación internacional de Perú. La hipótesis central del trabajo es que la cooperación china es un instrumento de su política exterior hacia Perú.

La información que se presenta a lo largo del documento se ubica en el periodo de gobierno del expresidente peruano Ollanta Humala Tasso (20112016), ya que en ese lapso se intensificaron las relaciones políticas entre Perú y China.

El estudio tiene dos partes. En la primera se analiza y se describe a conciencia la cooperación internacional entre Perú y China: modalidades de cooperación, principales actores, principales estadísticas, entre otros. En la segunda parte se hace un balance final donde se presentan las principales

4. Ayllón hace la diferencia conceptual entre ayuda externa y cooperación para el desarrollo de la siguiente manera: “Mientras que 'ayuda exterior' se refiere a un tipo de asistencia que puede no tener por objetivo último el desarrollo del país beneficiario - por ejemplo, las formas de ayuda militar o económica que buscan el interés del donante-, el término 'cooperación para el desarrollo', al menos nominalmente, significa que la meta explícita de esa modalidad de ayuda es el desarrollo, entendido como una iniciativa pactada de común acuerdo entre donante y receptor" (Ayllón, 2007, p. 36). 
conclusiones alcanzadas y recomendaciones de cómo potenciar la relación de cooperación entre ambos países en el futuro.

\section{La cooperación internacional entre Perú y China}

En esta sección se analizará la cooperación internacional entre Perú y China. Para ello, se comenzará por describir la relación política y económica entre ambos países, a modo de contexto. Luego, se describirá cómo es la cooperación de China con otros países (modalidades, temas, actores principales, etc.) y, después, se hará lo propio en el caso de Perú, a fin de comprender cómo es la cooperación con este país. Para ello, se analizarán la cooperación técnica, la cooperación financiera y la ayuda humanitaria por separado.

\section{Breve descripción de la relación entre Perú y China}

En 1841 arribó a China el primer barco peruano con fines comerciales. La inmigración china a Perú se inició en el año 1849, estimándose que más de 150,000 pobladores llegaron en un periodo de 25 años. ${ }^{5}$

En 1874 se suscribió el Tratado de Amistad, Comercio y Navegación entre Perú y China, que entró en vigencia a partir de marzo de 1876, luego de las ratificaciones en ambos países. En dicho instrumento legal se estableció lo siguiente: "Habrá paz y amistad entre la República de Perú y su Majestad el Emperador de la China. Sus respectivos ciudadanos y súbditos gozarán recíprocamente en los territorios de las Altas Partes Contratantes de la más completa y decidida protección en sus personas y propiedades".

Las relaciones diplomáticas se establecieron casi un siglo después, mediante el Comunicado Conjunto del 2 de noviembre del año $1971 .{ }^{6}$ Este documento estableció el común respeto a la soberanía de cada Estado, la convivencia pacífica, la no intervención en asuntos internos y el reconocimiento de Perú hacia el Gobierno de la República Popular China como el único representante legal del pueblo chino. Así, Perú se convirtió en el segundo país latinoamericano en reconocer a la República Popular China. Finalmente, el 28 de abril

5. Según cálculos, se estima que cerca del $10 \%$ de la población peruana tiene ascendencia china.

6. Este Comunicado fue ratificado por pronunciamientos presidenciales en los años 1994 y 1999. 
de 2009 ambos países firmaron el Tratado de Libre Comercio, que significó un nuevo capítulo para sus relaciones económicas.

\section{Interés actual de la relación entre Perú y China}

Entonces, ¿tiene el país sudamericano interés en reforzar sus relaciones políticas y comerciales con el gigante asiático? Y, ¿China comparte dicho interés? Hay cuatro factores que hacen inferir que la respuesta es afirmativa para ambos casos.

Primero, en los últimos años, ambos países han experimentado mayor integración comercial y económica, lo que se puede evidenciar en el aumento de las exportaciones e importaciones, siendo China para Perú uno de sus principales socios comerciales. La figura 1 muestra cómo las exportaciones peruanas hacia China han representado cada año un porcentaje mayor, por ejemplo, en 2011, las exportaciones peruanas hacia China representaron $15.2 \%$ de sus exportaciones totales; en 2012, 16.9\%; en 2013, 17.3\%; en 2014, 18.2\%; en 2015, 22.1\%; y en 2016, 23.6 por ciento.

\section{Figura 1}

Exportaciones peruanas (2006-2016)

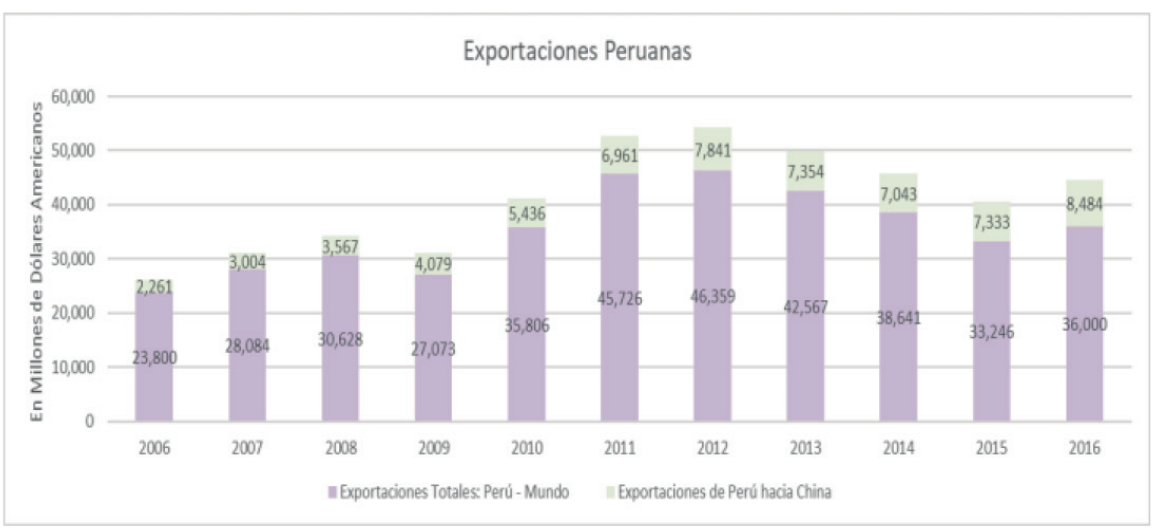

Fuente: elaboración propia con base en datos del Ministerio de Comercio Exterior y Turismo del Perú, 2017.

El aumento sostenido del comercio entre ambos países, de 2006 a 2016, se puede observar en la figura 2. De esta manera, aunque en los primeros años 
del gobierno humalista el saldo comercial para Perú fue ligeramente positivo, al final del periodo había crecido casi diez veces más que al inicio. Este crecimiento se vio vitalizado, además, por la firma del Tratado de Libre Comercio del 28 de abril de 2009, y por el aumento de las exportaciones tradicionales (minería, pesquería, gas y petróleo).

Las principales empresas exportadoras a China entre 2011 y 2016 fueron: Compañía Minera Antamina, Shougang Hierro Perú, Consorcio Minero (Cormin), Southern Peru Copper Corporation Sucursal del Perú, entre otras. Por otro lado, entre las principales empresas importadoras se cuentan: América Móvil Perú, Telefónica del Perú, Grupo Deltron, Huawei del Perú y Saga Falabella.

Segundo, el aumento de las inversiones chinas en Perú, en especial en los sectores tradicionales de la economía peruana, fue sostenido durante el periodo de análisis. La Figura 3 muestra la evolución de la inversión extranjera directa (IED) china en Perú desde el año 2000 hasta 2016. Como se puede ver, en el lapso de dieciséis años, la IED china en el país andino aumentó en casi $60 \%$. Esta IED entre 2011 y 2016 correspondió en su mayoría a los sectores de minería, finanzas y comercio. Además, las principales empresas receptoras fueron: Hexing Electrical Company, ICBC Perú Bank, Shougang Hierro Perú, Minería Shouxin Perú, Jinzhao Mining Perú. 
La cooperación internacional entre Perú y China (2011-2016)

Figura 2

Comercio entre Perú y China (en millones de USD)

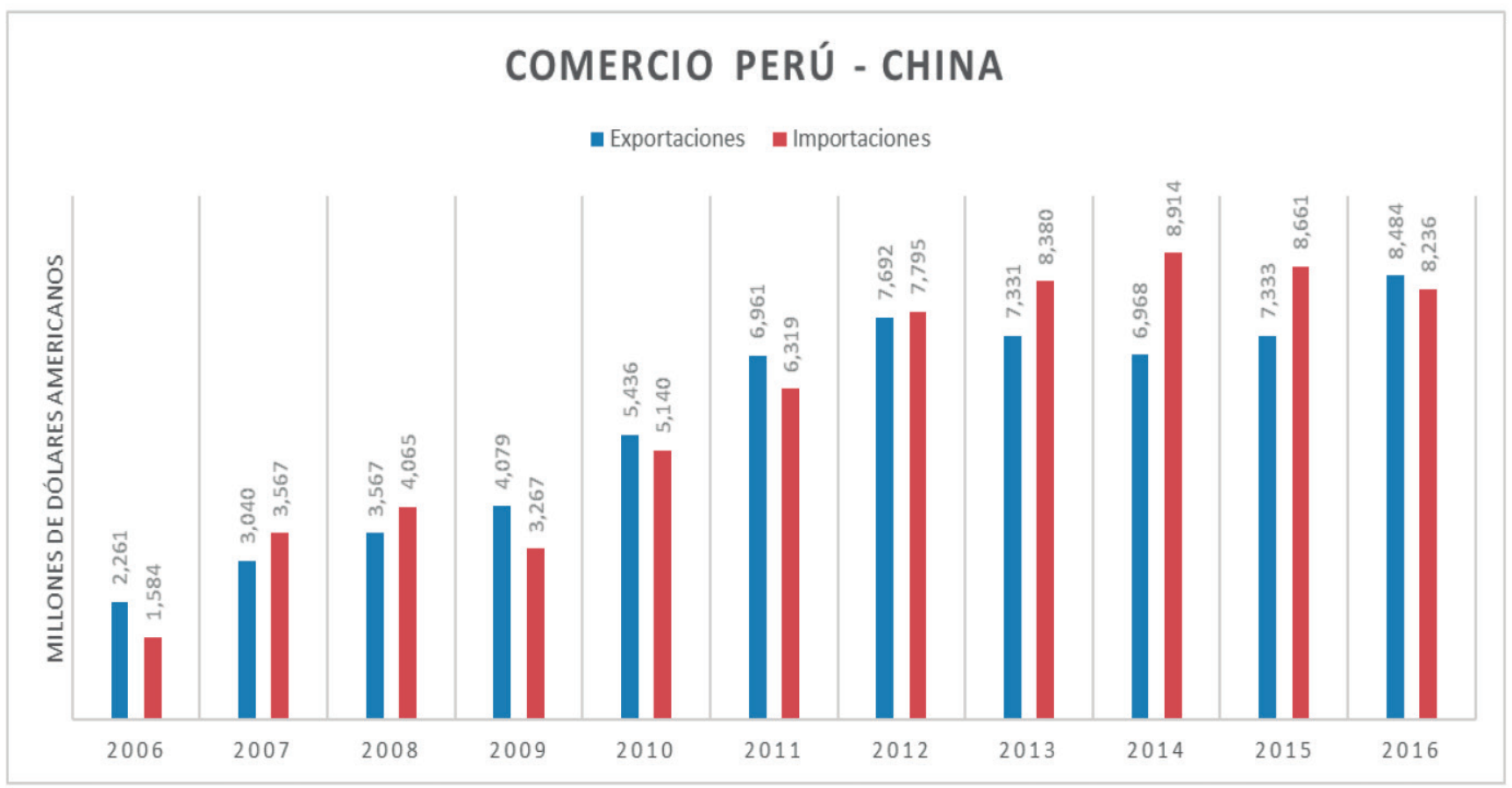

Fuente: elaboración propia con base en datos del Ministerio de Comercio Exterior y Turismo del Perú, 2017. 
Johana Lucar

Figura 3

La inversión extranjera directa china en Perú

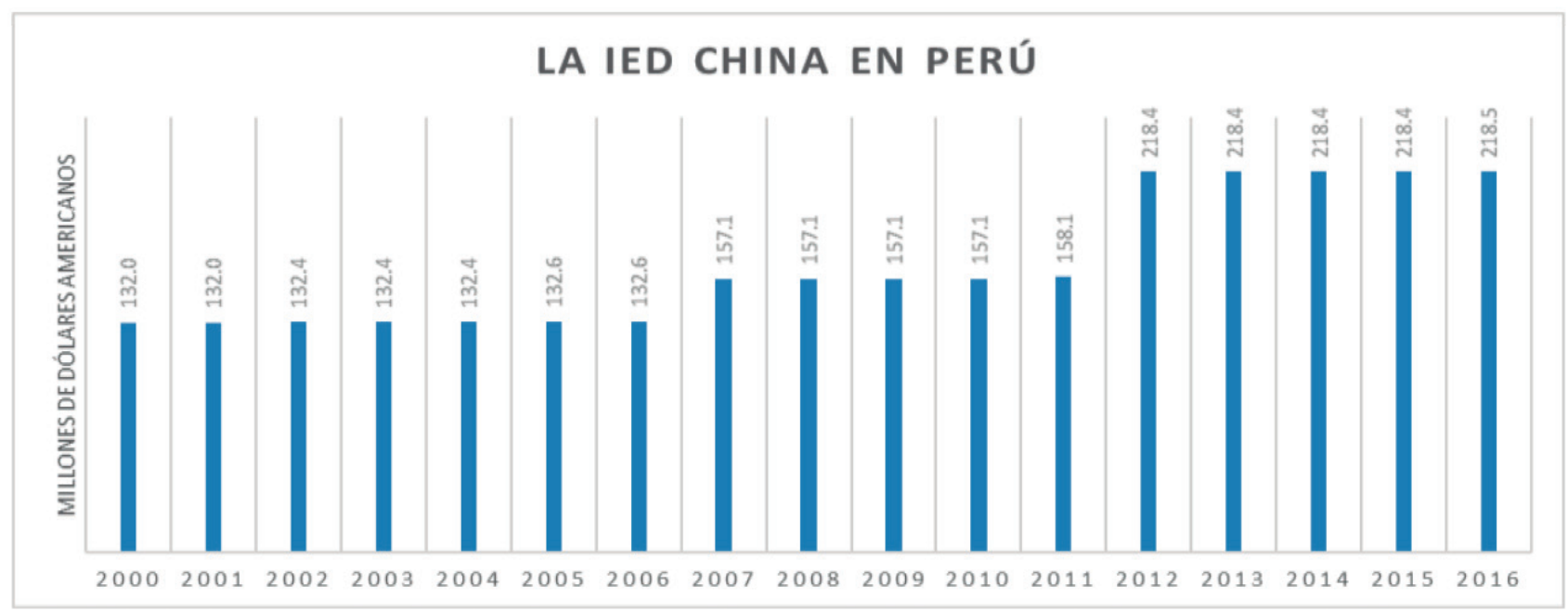

Fuente: elaboración propia con base en datos del Ministerio de Comercio Exterior y Turismo del Perú, 2017.

98 México y la Cuenca del Pacífico. Vol. 9, núm. 26 / mayo-agosto de 2020. 
Tercero, se ha producido un importante aumento del intercambio cultural entre ambos países: en el año 2013 se abrió en China el Centro de Estudios Peruanos en la Universidad Normal de Hebei (el primero en ese país). Asimismo, Perú ha comenzado a otorgar becas para estudiar en el gigante asiático y han aumentado las sedes de los institutos Confucio en el país andino.

Cuarto, hay un importante crecimiento de la cooperación china hacia Perú. Sobre este tema, se tiene que empezar por mencionar que, aunque en los años sesenta eran sólo tres los países considerados como donantes (Estados Unidos, Francia y Gran Bretaña), hoy en día no sólo los países desarrollados tienen a la cooperación internacional como componente importante de su política exterior, sino también los países en desarrollo (Cooperación Sur Sur). En ese contexto, se empieza a reconocer a China como uno de los más importantes cooperantes del mundo.

\section{La cooperación internacional entre Perú y China}

La cooperación entre Perú y China se inició en el año 1988 con la firma de dos instrumentos legales: el Acuerdo Básico de Cooperación Científica y Tecnológica ${ }^{7}$ y el Acuerdo Básico de Cooperación Económica y Técnica. ${ }^{8}$ Posterior a ellos, los Convenios de Cooperación Económica y Técnica que se suscriben cada año, mediante los cuales regula la cooperación para el financiamiento de proyectos.

En la actualidad, la cooperación entre ambos países es bilateral en diversos ámbitos, donde por lo regular Perú cumple el papel de receptor y China el de ofertante (aunque en los últimos años, Perú ha empezado a brindar cooperación técnica a China mediante becas de estudios).

\section{Características de la cooperación china}

La política exterior china tiene cuatro pilares: el mantenimiento de la integridad territorial, ser reconocido por la comunidad internacional como el único gobierno chino, propiciar el desarrollo económico del país e incrementar su prestigio en el ámbito internacional.

7. Firmado el 27 de enero de 1988.

8. Aprobado mediante Resolución Legislativa $N^{\circ} 25313$ de fecha 2 de abril de 1991. 
Para China, la cooperación internacional es un instrumento muy importante de su política exterior, ya que es la forma en que se vincula directa o indirectamente con ciertos países (en especial de África y Latinoamérica). Según el analista chino Hongcai (2016), China entregó 60 billones de dólares americanos $^{9}$ entre 1950 y 2013, como cooperación internacional, a 166 países y organizaciones internacionales.

En efecto, China se sumó a la cooperación internacional ${ }^{10}$ en 1950 , cuando donó materiales de asistencia humanitaria a Corea y Vietnam. En 1956 brindó cooperación internacional a África y, luego de su reincorporación a la ONU, intensificó relaciones económicas y de cooperación con otros países del orbe.

En la década de los noventa, China realizó una reforma en su política de cooperación internacional e hizo hincapié en la diversificación de las fuentes y los medios de financiación. En 1993, el Gobierno chino estableció un Fondo de Financiación para la Cooperación. Además, empezó a otorgar préstamos blandos a países en desarrollo.

Entre los años 2010 y el 2012, el gigante asiático destinó 13 billones de dólares americanos, ${ }^{11}$ aproximadamente, para cooperación internacional. Asia y África fueron los mayores beneficiarios: China brindó cooperación a 121 países en total (30 de Asia, 51 de África, nueve de Oceanía, 19 de Latinoamérica y 12 de Europa). En 2015, China concedió asistencia humanitaria a un total de 155 países y organizaciones y a 293 proyectos; asimismo, organizó 1,156 cursos y capacitó a 30,000 profesionales en China (Hongcai, 2016).

Las modalidades en las que China brinda cooperación internacional son las siguientes (Hongcai, 2016):

- Instrumentación de proyectos completos, en especial en los relacionados con infraestructura y agricultura.

- Provisión de bienes y servicios: equipo mecánico, equipo de inspección, vehículos de transporte, artículos de uso diario, medicina e implementos médicos.

9. El autor menciona que son 400 billones de yuanes, que al tipo de cambio del día 11 de abril del 2019 equivale a 59.6 billones de dólares americanos.

10. Cabe resaltar que para efectos del presente documento la ayuda humanitaria también se tendrá en cuenta al hablar de cooperación internacional.

11. El autor menciona que son 89.34 billones de yuanes, que al tipo de cambio del día 11 de abril del 2019 equivale a 13.24 billones de dólares americanos. 
- Cooperación técnica en los siguientes rubros: producción industrial, gerencia, agricultura, cultura y deporte, educación, educación física, cuidado médico y de la salud, desarrollo de energía limpia, asesoría.

- Capacitación de profesionales en China (becas de estudio).

- Servicios médicos.

- Programas de voluntarios. China envía voluntarios jóvenes y profesores de chino a más de 60 países.

- Asistencia humanitaria.

- Condonación de deuda a países con un bajo nivel de desarrollo y severamente endeudados. La cooperación financiera de China consiste en donaciones, préstamos sin intereses y préstamos preferentes. ${ }^{12}$

La cooperación china opera a través del Ministerio de Comercio Exterior y Cooperación Económica (MOFCOM). Los recursos de la cooperación china provienen del Tesoro Nacional de China.

En 2008, China elaboró y difundió el Documento sobre la Política hacia América Latina y el Caribe (primer libro blanco), donde describía los objetivos de la política china sobre dicha región, planteaba los principios que regirían la cooperación china y promovía así las relaciones sino-latinoamericanas y sino-caribeñas. En dicho documento se afirma: "El Gobierno chino se esforzará por establecer y desarrollar con los países latinoamericanos y caribeños la asociación de cooperación integral caracterizada por la igualdad, el beneficio recíproco y el desarrollo compartido" (Ministerio de Relaciones Exteriores de la República Popular China, 2008). Dicha cooperación estaba basada en los ámbitos de la inversión financiera, agrícola, industrial, construcción de infraestructuras, recursos y energía, aduanera, inspección de calidad y cuarentena, turismo, reducción y condonación de deudas, asistencia económica y técnica, cooperación multilateral, científica, tecnológica y educativa, entre otros.

En el 2011, China desarrolló el segundo ejemplar de su libro blanco titulado Desarrollo Pacífico de China, que describe la política de su cooperación internacional. La ayuda de China en el extranjero iba dirigida a los países en

12. La Organización para la Cooperación y el Desarrollo Económicos (OECD) define a los préstamos preferentes (Consessional loans) como "préstamos que se extienden en términos sustancialmente más generosos que los préstamos de mercado. La concesionalidad se logra a través de tipos de interés inferiores a los disponibles en el mercado o por períodos de gracia, o una combinación de estos. Los préstamos concesionales suelen tener períodos de gracia largos". Tomado de la página web de la OECD, disponible en https://stats.oecd.org/glossary/detail.asp?ID=5901, consultado en diciembre del 2017. 
desarrollo para reducir la pobreza y mejorar el nivel de vida de sus pueblos, anota el citado documento. Además, el libro blanco señalaba que China se comprometía a continuar incrementando su cooperación en el mundo: China continuará aumentando la información sobre asistencia extranjera, optimizando aún más la estructura de la asistencia, destacando aspectos clave, innovando los medios de asistencia, aumentando la eficiencia de la utilización del capital, ayudando efectivamente a los países receptores a mejorar el bienestar de sus personas y mejorando su capacidad de independencia. China está dispuesta a trabajar con la comunidad internacional para compartir oportunidades, enfrentar desafíos, esforzarse por realizar el sueño mundial de una paz duradera y la prosperidad común, y hacer una mayor contribución al desarrollo de la humanidad (Ministry of Foreign Affairs of the People's Republic of China, 2011).

\section{Características de la cooperación de Perú}

Hablar de la política exterior peruana es referirse a los cinco objetivos estratégicos y las 31 políticas de Estado del Acuerdo Nacional: "El compromiso de ejecutar una política exterior al servicio de la paz, la democracia y el desarrollo, mediante una adecuada inserción de Perú en el mundo y en los mercados internacionales, respetando los principios y normas del Derecho Internacional, en un marco de diálogo interinstitucional, incluyendo a las organizaciones políticas y a la sociedad civil", tal como lo afirma el Ministerio de Relaciones Exteriores del Perú (Ministerio de Relaciones Exteriores del Perú, 2016).

De este modo, el Plan Estratégico Sectorial Multianual 2015-2021 (PESEM/ RE 2015-2021), elaborado por la citada institución peruana, hace referencia directa al tema de la cooperación internacional en su Objetivo Estratégico $\mathrm{N}^{\circ} 4$, como se puede apreciar en la Tabla 1. 


\section{Tabla 1}

Plan Estratégico Sectorial Multianual 2015-2021

Plan Estratégico Sectorial Multianual 2015-2021 (PESEM/RE 2015-2021)

OBJETIVO ESTRATÉGICO N 4: Crear, ampliar y fortalecer lazos de intercambio, asociación y cooperación internacional a nivel regional y global para el desarrollo sostenible e inclusivo del país.

\begin{tabular}{l|l}
\hline 4.1 & $\begin{array}{l}\text { Desarrollar nuevos programas de cooperación técnica Sur-Sur, participar } \\
\text { activamente en los esquemas de cooperación triangular y promover nuevos } \\
\text { mecanismos, modalidades y esquemas de financiamiento para el desarrollo. }\end{array}$ \\
\hline 4.2 & $\begin{array}{l}\text { Fortalecer e implementar los mecanismos de cooperación en materia de } \\
\text { Ciencia y Tecnología e Innovación Tecnológica, vigentes entre Perú y los países } \\
\text { considerados prioritarios. }\end{array}$ \\
\hline 4.3 & $\begin{array}{l}\text { Fortalecer los mecanismos de cooperación y relacionamiento existentes en } \\
\text { materia de lucha contra las drogas y crimen organizado, en el ámbito bilateral, } \\
\text { regional y multilateral. }\end{array}$ \\
\hline 4.4 & $\begin{array}{l}\text { Promover la captación de recursos de cooperación en favor del desarrollo del } \\
\text { comercio, la mejora del proceso de diversificación productiva, la promoción de } \\
\text { inversiones y el fomento de las PYMES. }\end{array}$ \\
\hline 4.5 & $\begin{array}{l}\text { Poner en marcha mecanismos de cooperación Sur-Sur con países desarrollados } \\
\text { bajo un esquema de trabajo triangular. }\end{array}$ \\
\hline 4.6 & $\begin{array}{l}\text { Gestionar la cooperación internacional en áreas estratégicas de acuerdo a la } \\
\text { política nacional de cooperación técnica internacional. }\end{array}$ \\
\hline
\end{tabular}

Fuente: elaboración propia con datos del Ministerio de Relaciones Exteriores del Perú, 2016.

Por lo descrito anteriormente, se puede concluir que, para Perú, la difusión y el fortalecimiento de la gestión de la cooperación internacional parecieran ser estratégicos en su política exterior.

Como se sabe, la literatura especializada ofrece diversas clasificaciones de la cooperación internacional, según la naturaleza de las actividades, el origen de los recursos, el nivel de desarrollo, el número de fuentes y/o receptores involucrados, entre otros. En Perú, en la práctica, la cooperación internacional se gestiona y divide de acuerdo con la naturaleza de las actividades: cooperación técnica, cooperación financiera y asistencia humanitaria, tal como se puede apreciar en la figura 4. 
Figura 4

Gestión de la cooperación internacional en Perú

\section{Cooperación Internacional en Perú}

\section{Cooperación Internacional para el Desarrollo (CID)}

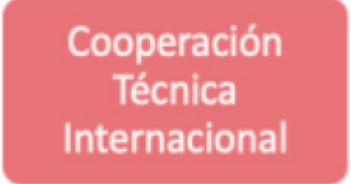

$\mathrm{APCl}$
Cooperación

Financiera

Reembolsable

PERU Ministerio

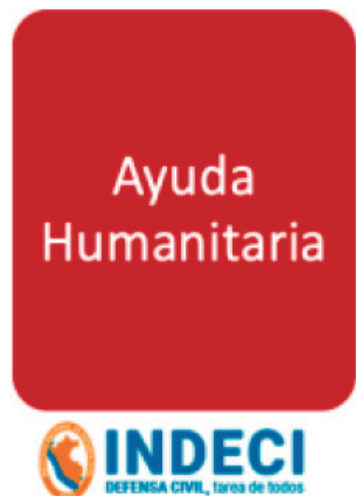

Derensa crvm, tares de bons.

Fuente: elaboración propia con datos de la Agencia Peruana de Cooperación Internacional (APCI, 2016b).

\section{Cooperación técnica peruana}

De conformidad con lo establecido en el artículo 3 de la Ley $\mathrm{N}^{\circ}$ 27692, Ley de creación de la Agencia Peruana de Cooperación Internacional, modificada por la Ley $\mathrm{N}^{\circ} 28925$, la APCI es el ente rector de la cooperación técnica internacional y tiene la responsabilidad de conducir, programar, organizar, priorizar y supervisar la cooperación internacional no reembolsable, que se gestiona a través del Estado y que proviene de fuentes del exterior de carácter público y/o privado, en función de la política nacional de desarrollo.

En ese sentido, la ley peruana ${ }^{13}$ define la cooperación técnica internacional como "el medio mediante el cual Perú recibe, transfiere y/o intercambia recursos humanos, bienes, servicios, capitales y tecnología de Fuentes Coo-

13. Decreto Legislativo $\mathrm{N}^{\circ} 719$, Ley de Cooperación Técnica Internacional, Art. $2^{\circ}$. 
perantes externas cuyo objetivo es complementar y contribuir a los esfuerzos nacionales en materia de desarrollo, destinados a: (a) apoyar la ejecución de actividades, proyectos y programas prioritarios para el desarrollo del país y de sus regiones, en especial en los espacio socioeconómicos, de mayor pobreza y marginación, (b) adquirir conocimientos científicos y tecnológicos para su adaptación y aplicación en Perú, así como facilitar a los extranjeros la adquisición de conocimientos científicos y tecnológicos nacionales, y (c) brindar preparación técnica, científica y cultural a peruanos en el país o en el extranjero y a los extranjeros en Perú".

Según la APCI, es importante incentivar la cooperación con China por la siguiente razón: "China, por su envergadura económica y de conocimientos, es muy atractiva (en el sentido de) contar con su apoyo en temas de asistencia técnica y donaciones de equipos". ${ }^{14}$ Por ello, dicha institución procura realizar las siguientes actividades para fomentar la cooperación con la República Popular de China:

- Atender los requerimientos realizados por China en referencia a los acuerdos de cooperación económica y técnica.

- Coordinar con la parte china y las instituciones públicas peruanas para la presentación de proyectos.

- Llevar a cabo reuniones de monitoreo de los proyectos en ejecución.

- Organizar visitas de evaluación a los proyectos en ejecución y a los que ya concluyeron.

En el caso de la cooperación técnica china con Perú, se realiza en las siguientes modalidades: asistencia técnica, desarrollo de infraestructura, suministro de equipos, capacitación y servicio de expertos y voluntarios. ${ }^{15}$ Adicionalmente, en la publicación "Situación y Tendencias de la Cooperación Internacional en Perú 2011-2014", la APCI (2016b) afirma que la cooperación de China con respecto a Perú ha seguido la siguiente tendencia (véase figura 5):

14. Información otorgada por la APCI (2016a) mediante Carta N 0081-2016/APCI-TRANSPARENCIA (02 de diciembre del 2016).

15. Información otorgada por la APCI (2016a) mediante Carta N 0081-2016/APCI-TRANSPARENCIA (02 de diciembre del 2016). 


\section{Figura 5}

La cooperación China con Perú (2008-2014)

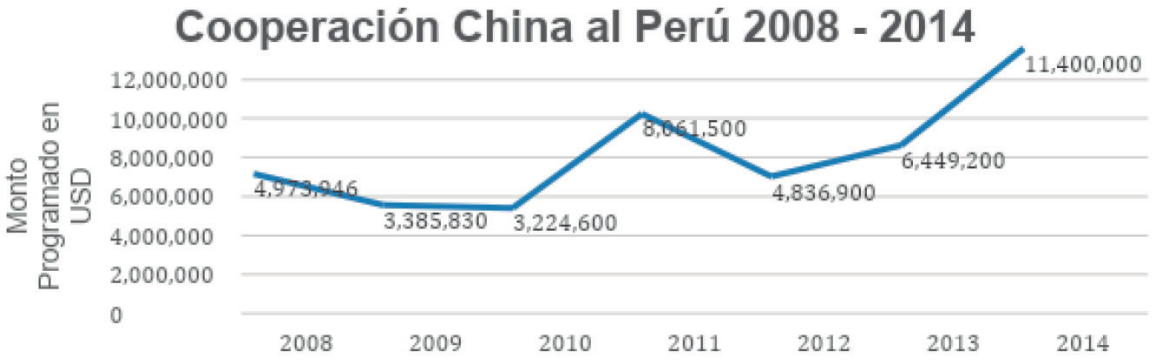

Fuente: elaboración propia con base en datos del MIPCI, SIGO ${ }^{16}$ ("Situación y Tendencias de la Cooperación Internacional en el Perú 2011-2014").

Aunque no se tiene el detalle del presupuesto total de la cooperación técnica de China en Perú en los años mencionados, se ha logrado conseguir información de algunas intervenciones, proyectos y/o actividades (en referencia al desarrollo de infraestructura, donación de equipos) realizadas entre el año 2012 y el 2015, según información proporcionada por la APCI. Para el año 2016, de acuerdo con esta institución, las intervenciones chinas en Perú en materia de cooperación técnica fueron siete: Seminario de Planificación y Construcción de Infraestructura para los Países Hispanohablantes (en agosto de 2014), la construcción del Centro de la Amistad Peruano Chino (entre agosto de 2012 y octubre de 2014), la donación de material antifriaje y bajas temperaturas (entre enero de 2014 y diciembre de 2015), la construcción de la Escuela Primaria núm. 20602, José María Arguedas, Santa Cruz de Cocachacra, Huarochirí (entre enero de 2012 y diciembre de 2015), entrega de motocicletas fumigadoras para combatir la roya amarilla (entre enero de 2014 y enero de 2015), la transmisión de equipos biomecánicos para la instrumentación de los servicios que brinda el MIPV (entre enero de 2014 y diciembre de 2015), la construcción del Centro de Operaciones de Emergencia Nacional - COEN(entre enero de 2014 y diciembre de 2017).

16. El Sistema Integrado de Gestión Operativa (SIGO) es una plataforma informática manejada por la APCI, en la cual se registran las intervenciones financiadas con recursos de la CINR a través de los siguientes trámites administrativos: Registro de proyectos y plan de operaciones, Registro de proyectos efectuados por los responsables de fuentes oficiales (Ayuda Oficial al Desarrollo - AOD). 
La República Popular China proporciona becas para cursos que ofrece dicho Gobierno en diversas áreas a ciudadanos peruanos. También se otorgan becas para estudiar carreras universitarias tanto de pregrado como de posgrado, en amplios campos de estudio.

En Perú, la información estadística referida a la participación de profesionales y técnicos peruanos, así como la difusión de la relacionada con las becas, es administrada por el Programa Nacional de Becas y Crédito Educativo (Pronabec). Según información de dicha institución, entre los años 2012 y 2015 , fueron 11,554 las becas que se entregaron a ciudadanos peruanos para seguir estudios en el extranjero gracias a la cooperación internacional: "Son 51 becarios los beneficiados para realizar estudios superiores en China: 30 por otorgamiento directo, 10 a través de Beca Reciprocidad Perú-China, ${ }^{17} 6$ por el Concytec ${ }^{18}$ y 5 por la Agencia Peruana de Cooperación Internacional-APCI" (PRONABEC, 2015) en cuestiones como: administración de empresas, comunicaciones, logística, medicina forense, pedagogía, economía, entre otros.

Con respecto a los expertos y voluntarios chinos que vienen a Perú, hay que mencionar que éstos superan en más de cinco veces a los expertos entre 2011 y el 2015, como se puede apreciar en la Figura 6.

17. La Beca de Reciprocidad Perú - China surgió a raíz de un convenio con la República de China para permitir que ciudadanos peruanos puedan seguir estudios de postgrado en universidades chinas, en la modalidad presencial a tiempo completo. La beca se otorga por el tiempo equivalente a la duración del programa, establecido por el plan de estudios y el cronograma entregado por la institución de educación superior extranjera. El máximo es de dos años para maestrías y cuatro años para doctorado.

18. El Consejo Nacional de Ciencia, Tecnología e Innovación Tecnológica (Concytec) es la institución peruana rectora del Sistema Nacional de Ciencia y Tecnología e Innovación Tecnológica (Sinacyt), integrada por la Academia, los institutos de investigación del Estado, las organizaciones empresariales, las comunidades y la sociedad civil. Está regida por la Ley Marco de Ciencia y Tecnología $\mathrm{N}^{\circ} 28303$. 


\section{Figura 6}

Número de expertos y voluntarios chinos enviados a Perú

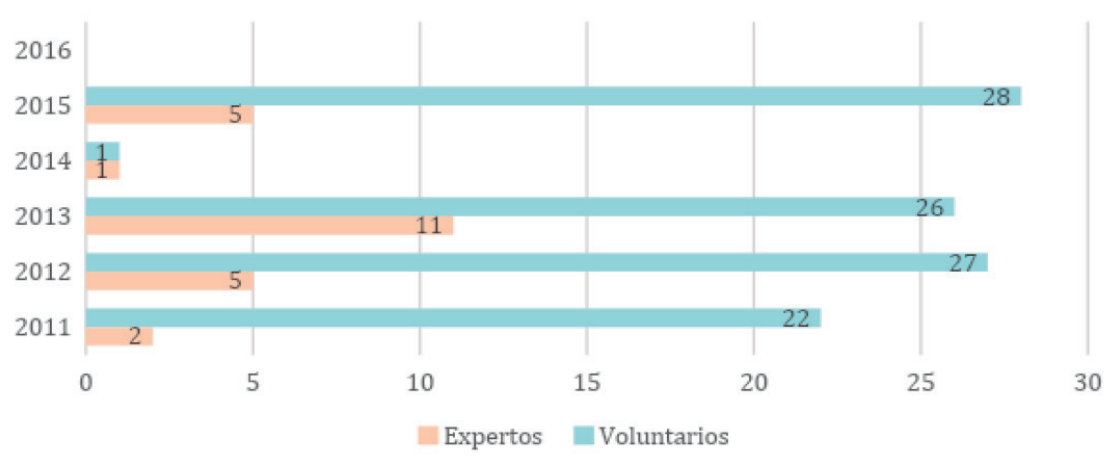

Fuente: elaboración propia con base en datos de la APCI, 2016b.

Cabe mencionar que los voluntarios chinos son profesionales o técnicos relacionados con el objetivo y el resultado del proyecto, mientras que los expertos chinos llegan a Perú para apoyar actividades del proyecto aprobado y su permanencia varía de acuerdo con éste. En ambos casos, las mayores dificultades que encuentran los expertos y/o voluntarios que llegan a Perú son el idioma y las diferencias culturales.

El proceso que sigue Perú (en este caso, la APCI) para obtener cooperación técnica procedente de China se describe en la figura 7: 


\section{Figura 7}

Proceso que sigue Perú para contar con la cooperación técnica de la República Popular China

\section{Convocatoria de China}

APCI difunde y selecciona proyectos entre las entidades públicas (durante todo el año)

Los proyectos seleccionados son presentados a la Embajada de la República Popular China en Perú

La embajada selecciona los proyectos que apoyará con cooperación técnica

Suscripción de Acuerdo de Cooperación Económica y

Técnica para financiar los proyectos seleccionados.

Fuente: elaboración propia con base en datos de la APCI, 2016b.

Lo más sobresaliente, en el caso de la cooperación técnica, es que, aunque la APCI es la institución pública peruana encargada de canalizarla, no tiene un registro real de la cooperación china con Perú. Esto sucede porque China, por medio de su embajada en Perú, gestiona cooperación (en especial becas) directamente. Ello puede representar un problema potencial en el futuro, ya que podría generarse un conflicto de intereses: imaginemos que el Estado peruano tiene que decidir si compra medicamentos a China, y el funcionario público encargado fue beneficiario de una beca en dicho país. El problema se solucionaría si la información de los beneficiarios de becas otorgadas por otros países a la población peruana fuese transparente.

\section{Cooperación financiera reembolsable peruana}

El Ministerio de Economía y Finanzas define la cooperación financiera como "cooperación que, mediante la transferencia monetaria real de fondos al receptor, permite desarrollar proyectos o actividades que beneficien a una institución o país. Puede ser de fondos reembolsables o no reembolsables, 
dependiendo de si la transferencia debe ser devuelta al país emisor o si la transferencia ha sido efectuada a fondo perdido (donación)" (Ministerio de Economía y Finanzas, 2016).

De acuerdo a la Ley 28563, "Ley General del Sistema Nacional de Endeudamiento", el ente rector del Sistema Nacional de Endeudamiento es la Dirección General de Endeudamiento y Tesoro Público del Ministerio de Economía y Finanzas del Perú.

En el artículo 3 de la mencionada ley, se definen las operaciones de endeudamiento externo público como "financiamiento sujeto a reembolso acordado a plazos mayores de un año, destinado a la ejecución de proyectos de inversión pública, la prestación de servicios, el apoyo a la balanza de pagos y el cumplimiento de las funciones de defensa nacional, orden interno y previsional a cargo del Estado (...)". Además, se define la deuda externa como "aquellas acordadas con personas naturales o jurídicas no domiciliadas en el país (...)".

El Perú mantenía, hasta el año 2016, una deuda externa pública total de \$24,391 millones de dólares americanos, tal como se puede apreciar en la figura 8.

\section{Figura 8}

Deuda total pública de mediano y largo plazos

\section{Deuda Externa Pública Peruana (al 30/09/2016)}

\begin{tabular}{|c|c|}
\hline \multicolumn{2}{|c|}{$\begin{array}{c}\text { Deuda Pública Peruana } \\
\text { de mediando y largo plazo }\end{array}$} \\
\hline Tipo de Deuda & Millones de US\$ \\
\hline Deuda Extema & 24,391 \\
\hline Deuda Interna & 20,358 \\
\hline TOTAL & $\mathbf{4 4 , 7 4 9}$ \\
\hline
\end{tabular}

\begin{tabular}{|l|c|}
\hline \multicolumn{2}{|c|}{$\begin{array}{c}\text { Deuda Pública Externa de Mediano y Largo Plazo } \\
\text { por paises }\end{array}$} \\
\hline \multicolumn{1}{|c|}{ Miles de Us\$ } \\
\hline Alemania & 507,660 \\
\hline Bélgica & 837 \\
\hline Estados Unidos & 33,644 \\
\hline Francia & 63,975 \\
\hline Italia & 13,332 \\
\hline Japón & $1,038,472$ \\
\hline Multinacional - Bancos & 882,635 \\
\hline Multinacional - Bonos & $15,387,150$ \\
\hline Multinacional - Organismos Intemacionales & $6,459,841$ \\
\hline Países Baios & 3,382 \\
\hline \multicolumn{1}{|c}{ T O T A L } & $\mathbf{2 4 , 3 9 0 , 9 2 8}$ \\
\hline
\end{tabular}

Fuente: elaboración propia con base en datos del Ministerio de Economía y Finanzas del Perú, 2016 . 
Como se puede observar, hasta 2016, China no había sido acreedor de Perú, es decir, Perú no había recibido ayuda financiera gubernamental de dicho país. ${ }^{19}$ Además, el Ministerio de Economía y Finanzas de Perú ${ }^{20}$ no tenía previsto concertar alguna operación financiera reembolsable con el citado país en un futuro próximo. Si China se convirtiese en acreedor de Perú, lo podría poner en una situación ventajosa ante negociaciones comerciales y/o políticas. Por ello, es importante que el Ministerio de Economía y Finanzas del Perú trabaje de manera coordinada con el Ministerio de Relaciones Internacionales y otras instituciones públicas de interés.

\section{Asistencia humanitaria en Perú}

En el Compendio Estadístico 2016, elaborado por el Instituto Nacional de Defensa Civil (Indeci), se definió la asistencia humanitaria como "el conjunto de acciones oportunas, adecuadas y temporales que ejecutan las entidades integrantes del Sistema Nacional de Gestión de Riesgo de Desastres-Sinagerd- en el marco de sus competencias y funciones, para aliviar el sufrimiento, garantizar la subsistencia, proteger los derechos y defender la dignidad de las personas damnificadas y afectadas por los desastres".

En el DS 043-2013-PCM, de fecha 19 de abril de 2013, se publicó el Reglamento de Organización y Funciones del Instituto Nacional de Defensa Civil (Indeci), en el que se establece en el Título Primero "De las disposiciones generales de la naturaleza jurídica, entidad de la que depende, jurisdicción, funciones y base legal”, en el art. 4 "De las Funciones Generales de Indeci", lo siguiente: "(m) coordinar la participación de entidades y agencias de cooperación nacional e internacional para los procesos de preparación, respuesta y rehabilitación; (o) coordinar la asistencia humanitaria solicitada por los países afectados por desastres en el marco de convenios o acuerdos establecidos, conforme a la normatividad vigente; (s) proponer al Ente Rector la normativa para la coordinación y distribución de los recursos de ayuda humanitaria”.

Para efectos del presente documento, interesa saber si Perú ha recibido asistencia humanitaria por parte de China. Por ello, se hizo la consulta a

19. No se incluye la deuda que China haya podido generar a empresas privadas.

20. Según lo informado por el Ministerio de Relaciones Exteriores en el Oficio N 4271-2016-EF/45.01 (del 24 de noviembre del 2016). 
Indeci, que respondió ${ }^{21}$ que la Embajada de la República Popular China en Perú efectuó las siguientes donaciones de bienes de ayuda humanitaria: 887 calaminas $^{22}$ (valorizado en USD 5,000) en 2015 y 34 contenedores $^{23}$ nuevos en 2016.

En este apartado se ha hecho un estudio de cómo se gestiona la cooperación entre Perú y China. A continuación se presentará un balance general de lo descrito, para conocer las implicancias de la cooperación internacional en las relaciones entre ambos países.

\section{Comentarios finales: una mirada desde Perú}

La cooperación para el desarrollo, tal como lo conocemos hoy en día, hereda muchas de sus características de la época en la que surgió. Durante la Guerra Fría se concibió la fórmula donante-receptor, donde el primero buscaba el desarrollo del segundo, pero sin la intervención de él. Esta ayuda respondía entonces a los intereses de los donantes más que a las necesidades de los receptores. Hoy, esta ecuación ha evolucionado, en teoría (teniendo en cuenta los principios de la Declaración de París de 2005), aunque en la práctica queda mucho camino por recorrer.

Es innegable el creciente interés que ha mostrado China por Perú. Queda también claro por qué: el aprovechamiento de los recursos naturales (en especial, minerales) del país andino. En los últimos años, este acercamiento se ha intensificado en cuestiones económicas: comercio e inversión, que tienen sustento en los distintos instrumentos legales que han firmado.

Entonces, la hipótesis planteada al inicio del documento (la cooperación china es un instrumento de su política exterior hacia Perú) es aceptada como verdadera. La cooperación china en Perú se puede concebir como un instrumento de la política exterior del gigante asiático que le permite afianzar los objetivos económicos que tiene en dicho país, de acuerdo con la teoría realista de las Relaciones Internacionales. Las evidencias indican que China no brinda ayuda a Perú únicamente porque busca el desarrollo del país andino, sino como una forma de acercarse e intensificar las relaciones políticas y económicas con él.

21. La respuesta fue entregada a través de la Resolución Jefatural Nº11-2015-INDECI (30 de enero del 2015) y la Resolución Jefatural Nº22-2016-INDECI (04 de febrero del 2016).

22. Calaminas SIDEPERU acero galvanizado T/Corrugado de 0.22 MM X 1.8 MT X 0.831 MM ONDULADO $22 \mathrm{MM}$.

23. Contenedores de 40 pies con 10,861 paquetes, portando materiales antifriaje. 
Por su parte, Perú considera a China como un actor internacional importante en su política exterior y más aún para su economía doméstica. Entonces, la posición de Perú frente al gigante asiático debe ser más estratégica en cuanto tema la cuestión de la cooperación. ¿Cómo puede lograrse esto?

Primero, debiera existir coordinación entre las instituciones encargadas de la cooperación técnica y financiera (APCI y el Ministerio de Economía y Finanzas, respectivamente), a fin de tener el panorama claro en todo momento. Hasta 2016, Perú no tenía ninguna deuda pública con China, pero si en algún momento esto ocurriese, el Ministerio de Relaciones Exteriores debería estar al tanto. La adopción de deuda externa con un país determinado cambia por completo el tipo de relación posible entre el país acreedor y el deudor.

Segundo, es recomendable que se establezca una estrategia determinada con la cooperación técnica que China brinda. En este caso, la APCI debería estar al tanto de toda la cooperación técnica del gigante asiático con Perú. hoy en día no ocurre esto. Por ejemplo, en cuestión de becas, algunas son canalizadas vía Pronabec y la APCI, pero otras son gestionadas directamente por medio de la Embajada de China en Perú, siendo aquélla la que decide qué personas se benefician con esta modalidad de cooperación. ¿Qué pasaría si China empezara a brindar becas de estudios cortos (o de maestría, doctorado, etc.) a personas de un partido político en especial?, ¿no significaría esto que podría existir un posible conflicto de intereses?

Tercero, debiera existir una política de transparencia de los beneficiarios de la cooperación técnica que China brinda. En este caso, la APCI tendría que ser la encargada de mantener un registro de todas las instituciones y/o personas beneficiadas de la ayuda proveniente de China. En el caso de las becas, debiera ser el Pronabec el que mantenga esa base de datos. Corresponde que toda esta información esté al alcance del público en general de manera clara y rápida.

Cuarto, el Gobierno peruano debe contar con funcionarios capacitados en el idioma chino y la cultura china, ya que ello facilitaría la comunicación con dicho país y sería muy importante al momento de negociar la cooperación internacional que Perú recibe del citado país.

Finalmente, Perú tiene que convertirse en un ofertante de cooperación internacional hacia China. Hasta el momento, Perú sólo le ofrece cooperación técnica a través de becas de estudios; pero sería interesante que empezara a ver la cooperación internacional como una herramienta de su política exterior, a fin de enriquecer la relación con dicho país; del mismo modo que el país del sol naciente lo hace con Perú. 


\section{Referencias}

Agencia Peruana de Cooperación Internacional (APCI). (2016a). Carta $N^{\circ}$ 0081-2016/APCI-TRANSPARENCIA.

Agencia Peruana de Cooperación Internacional (APCI). (2016b). Situación y Tendencias de la Cooperación Internacional en el Perú 2011 - 2014. Recuperado de https://issuu.com/apci_peru/docs/situacion_y_tendencia

Ayllón, B. (2007). La cooperación Internacional para el Desarrollo: fundamentos y justificaciones en la perspectiva de la Teoría de las Relaciones Internacionales. Carta Internacional, pp. 25-40.

Bonilla, A. \& Milet, P. (Eds.) (2015). China en América Latina y el Caribe: Escenarios estratégicos subregionales. San José: Banco de Desarrollo de América Latina.

Calduch C. R. (1995). Relaciones internacionales. Madrid: Ciencias Sociales.

Cesarín, S. \& Moneta, C. (Eds.) (2005). China y América Latina, nuevos enfoques sobre cooperación y desarrollo ¿Una segunda ruta de la seda? Buenos Aires: Instituto para la integración de América Latina y el Caribe.

Comisión Económica para América Latina y el Caribe (CEPAL). (2012). La República Popular China y América Latina y el Caribe: Diálogo y cooperación ante los nuevos desafíos de la economía global. Santiago de Chile: Naciones Unidas.

Confucius Institute Headquarters (Hanban) (2018). Recuperado de http:// english.hanban.org/

Decreto Legislativo $\mathrm{N}^{\circ} 719$. Ley de Cooperación Técnica Internacional.

Hongcai, X. (2016). Introduction of China's foreign aid policy. Paper for Aid as External Economic Policy: Cases of Japan and China, Tokio, Japón. Resumen recuperado de http://www.cciee.org.cn/UserFile/201622146.pdf

Instituto Nacional de Defensa Civil (INDECI). (2016). Compendio Estadístico del Indeci 2016 en la preparación, respuesta y rehabilitación ante emergencias y desastres. Lima, Perú: Instituto Nacional de Defensa Civil.

León, R. I., \& Gachúz J, (2015). Política Exterior China: relaciones regionales y cooperación. Puebla, México: Programa de Fortalecimiento de la Calidad en Instituciones Educativas.

Mantilla, S. (Ed.). (2015). La expansión de China en América Latina. Centro Latinoamericano de Estudios Políticos. Quito, Ecuador: Centro Latinoamericano de Estudios Políticos. 
Ministerio de Comercio Exterior y Turismo del Perú (2017). Recuperado de https://www.gob.pe/mincetur

Ministerio de Economía y Finanzas del Perú (2016). Recuperado de https:// www.mef.gob.pe/es/glosario-sp-10805

Ministerio de Relaciones Exteriores de la República Popular China. (2008). Texto íntegro del Documento sobre la Política de China hacia América Latina y el Caribe. Recuperado de https://www.fmprc.gov.cn/esp/zxxx/t521035. shtml

Ministerio de Relaciones Exteriores del Perú (2016). Oficio $N^{\circ} 4271-2016$ EF/45.01. Recuperado de http://www.rree.gob.pe/politicaexterior/ Paginas/Home.aspx

Ministry of Foreign Affairs of the People's Republic of China. (2011). Libro Blanco: Desarrollo Pacífico de China. Recuperado de https://www.fmprc. gov.cn/esp/zxxx/t862206.shtml

Organización para la Cooperación y el Desarrollo Económico (OECD). (2017). Glossary of Statistical Terms. Recuperado de https://stats.oecd.org/glossary/detail.asp?ID=5901

Programa Nacional de Becas y Crédito Educativo (PRONABEC) (2015). Memoria Institucional 2012-2015. Ministerio de Educación del Perú. Perú: Programa Nacional de Becas y Crédito Educativo, Ministerio de Educación. 